\title{
Fernando de Magallanes: la creación del mito del héroe
}

\section{Ferdinand Magellan: The Creation of the Hero Myth}

\section{Marguerite Cattan}

Manhattanville College

ESTADOS UNIDOS

margueritecattan@gmail.com

[Hipogrifo, (issn: 2328-1308), 6.1, 2018, pp. 535-553]

Recibido: 14-08-2017 / Aceptado: 26-09-2017

DOI: http://dx.doi.org/10.13035/H.2018.06.01.37

Resumen. El presente artículo analiza la manera en que los tratados historiográficos construyeron la imagen de Fernando Magallanes como héroe a través de los años y cómo se creó su mito. La persona histórica una vez heroizada tiende a crear su propio mito que contiene, en muchos casos, verdades que no pueden verificarse como históricas. Como resultado es el héroe mítico y no el personaje histórico el que queda impreso en la conciencia colectiva.

Palabras clave. Crónicas de Indias; Fernando de Magallanes; mito; héroe.

Abstract. This article analyses the way in which historiographical studies built the image of Ferdinand Magellan as hero and how his myth was created over the years. Once the historical person is heroized he creates his own myth that contains, in many cases, truths which cannot be verified as historical. As a result it is the mythical hero and not the historical character which remains imprinted in the collective consciousness.

Keywords. Chronicles of the Indies; Ferdinand Magellan; Myth; Hero. 
predestinado para altas empresas y glorias inmortales

Latino Coelho

Durante la época de viajes y exploraciones de América, las gestas de los protagonistas rememoraron un remoto pasado de héroes míticos en sus navegaciones a lejanas tierras como el encuentro con mundos desconocidos y admirables. Las hazañas de aquellos navegantes, exploradores y conquistadores no solo aportaron fama y distinción a sus nombres sino que también sus acciones se tildaron de heroicas. Los héroes del descubrimiento y la conquista brindaron un sentimiento de orgullo al pueblo español y la historia que se creó alrededor de ellos proporcionó una identidad propia, destacada y superior, digna del creciente imperio español; una historia que los distinguió y separó del resto de los europeos.

El presente estudio no presenta un juicio de valor sobre las hazañas de los exploradores y conquistadores ni tampoco confirma o desmiente que esos hombres efectuaron un esfuerzo eminente de la voluntad, hecho con abnegación, que los llevó a realizar actos extraordinarios (definición de heroísmo según la RAE). Más bien se intenta postular que los principales descubridores y conquistadores de América no solo se convirtieron en personas ilustres y famosas por sus hazañas o virtudes (definición de «héroe» según la RAE), sino que dentro de ese proceso de heroización sus historias llegaron a mitificarse; es por ello que este estudio se centra en este último punto: la mitificación de sus historias.

Mi interés es la revisión de cómo el personaje histórico se va desdibujando y borrando, abriendo paso a un personaje prácticamente mítico. La persona históri$\mathrm{ca}$, una vez heroizada, tiende a crear su propio mito que contiene, en muchos casos, verdades que no pueden verificarse como históricas y en consecuencia es el mito el que se imprime en la conciencia colectiva. El personaje que he elegido para ejemplificar mi tesis es Fernando de Magallanes, cuyas hazañas brindaron gloria a España, pese a que, por ser extranjero, algunos coetáneos suyos lo miraron con recelo y presentaron impedimentos en la admisión de sus logros, sin olvidar que sus compatriotas lo tildaron de traidor ${ }^{1}$. A pesar de estos inconvenientes, Magallanes se convierte en héroe y su historia ejemplifica cómo se llega a mitificar al héroe de la conquista de América.

En las líneas que siguen, no deseo justificar la parte histórica de este personaje, sino revisar el proceso de cómo se desvanece el personaje histórico y se convierte

1. El hecho de que Magallanes dejara su patria para ofrecer sus servicios a Castilla es un acto que pocos historiadores portugueses perdonaron, pues en aquella época «Desnaturalisar-se de portuguez e ir offerecer a sua espada aos reis catholicos era porventura maior sacrilégio, então, do que renegar a pureza da verdadeira fé, e transviar-se nos erros de Luthero e de Calvino», en Latino Coelho, 1917, pp. 141-142. A partir de las últimas décadas del siglo XIX y principios del siglo XX, los historiadores portugueses han intentado justificar las acciones y reivindicar el nombre de ese hijo de la patria; entre ellos podemos mencionar a Queiroz Velloso y Lagôa. 
en mito. Como punto de partida, utilizo los estudios de Fitzroy Raglan y Joseph Campbell para analizar el mito del héroe, que más adelante aplico a la biografía de Magallanes establecida por los historiadores.

\section{RAGLAN Y CAMPBELL}

Fitzroy Raglan y Joseph Campbell se dedicaron, en diferentes épocas, a estudiar mitos de héroes y encontraron que entre ellos existen grandes afinidades. Ambos académicos proponen que el mito del héroe sigue un mismo patrón. Patrón que también se encuentra en el mito de Fernando de Magallanes.

En 1936, Raglan examina las historias de varios héroes universales y las divide en incidentes separados, descubriendo que ciertos tipos de incidentes ocurren en todas las historias. Raglan sostiene que las figuras heroicas de la mitología comparten un patrón común que satisface el deseo humano de idealización y provee una lista de veintidós similitudes entre los mitos de héroes, que distribuye en tres grupos: incidentes sobre el nacimiento del héroe, su ascensión al trono y su muerte. Para él, el hecho de que la vida de un héroe de la tradición mítica pueda ser dividida en una serie de marcadas características y sucesos sugiere un patrón ritual².

Campbell, en 1949, realiza una labor parecida, encontrando que los mitos comparten una estructura fundamental. Campbell analiza una serie de mitos de diferentes culturas y épocas y busca demostrar los elementos universales entre estos. Partiendo de las teorías de Jung, su lectura de los mitos es más simbólica y advierte que los mitos revelan un lado desconocido de la personalidad. Él encuentra que la aventura mitológica del héroe -lo que él denomina el viaje del héroe- sigue una ruta estándar, siendo esta una magnificación de los ritos de paso: separacióniniciación-retorno. La aventura del héroe, según Campbell, normalmente sigue el modelo de la unidad nuclear: una separación del mundo, una penetración en alguna fuente de poder, y un retorno que mejora la vida.

Ambos académicos analizan mitos universales y aplican su método no solo a héroes mitológicos, sino también a personajes históricos. En cuanto a los héroes con un pasado histórico, los dos llegan a la conclusión de que la persona histórica y el héroe mítico, aunque comparten el mismo nombre, en realidad son personas muy diferentes. Campbell advierte que no se debe confundir la historia mítica del héroe - sea este Jesús, Buda o Mohamed - con la del hombre histórico. Sus historias, dice Campbell, son las que nos conciernen, el héroe puede o no puede haber sido histórico, la vida del hombre es secundaria. El énfasis de este elemento histórico solo daría lugar a confusión; nos llevaría simplemente a confundir la imagen del mensaje ${ }^{3}$. La persona histórica, una vez heroizada, tiende a crear su propio mito -y es su mito lo que nos interesa. El mito del héroe con el tiempo se desarrolla, amplía, evoluciona y, en consecuencia, cambia. Las siguientes páginas se enfocan en esta 
noción: cómo el mito del héroe Magallanes se desarrolla, crece y se sobrepone al personaje histórico.

Ambos autores advierten que pocos mitos contienen todas las incidencias o etapas. Si bien, algunos mitos contienen muchas de ellas, otros contienen solo unas pocas, o tienen como foco una de las etapas. Además, las incidencias o etapas no necesariamente siguen un orden predeterminado.

No es la intención este estudio comparar, contrastar o afirmar una u otra teoría -no obstante cabe mencionar que la tesis de Campbell es más citada- el interés se centra en enfocarnos en dos ideas que Raglan y Campbell comparten: las historias de los héroes tienen puntos en común y las historias de los héroes históricos se convierten en mitos tras su muerte. Siguiendo estas dos premisas, deseo ilustrar los incidentes que la historia de este navegante comparte con los héroes míticos - para ello utilizo indistintamente ambos estudios- y cómo tras su muerte no es el Magallanes histórico el que queda impreso en la conciencia colectiva sino su historia mítica.

\section{EL MITO-HISTORIA DE FERNANDO DE MAGALLANES}

A fin de comprender la creación del mito de Magallanes creo necesario repasar su historia tal y como los escritores, a través de los años, la han contado y recontado. Las obras consultadas datan de los siglos XVI al XX y todas ellas se reconocen como tratados historiográficos en cuanto intentan una proposición fáctica de la expedición de Magallanes ${ }^{4}$. Lo interesante es que en todas estas obras se percibe una mezcla del recuento de los hechos históricos con ciertas aseveraciones sobre la vida del navegante que provienen de suposiciones u opiniones de los autores. De esta manera, la biografía de Magallanes se va fusionando con la historia mítica del héroe y el personaje mítico se va forjando.

Si bien los variados escritos sobre el navegante portugués fueron motivados por razones muy diversas, la mayoría de autores comparten el compromiso de ensalzar al personaje y su hazaña y, así, contribuyen a construir la figura del héroe y, por tanto, crear su mito. Inclusive los autores portugueses, coetáneos a Magallanes, quienes lo juzgaban como traidor a la corona portuguesa no dejan, en ocasiones, de reconocer su valía.

En la siguiente relectura del mito-historia de Magallanes se han combinado deliberada e indistintamente las fuentes, pues es a partir de la suma de ellas que la noción colectiva de este personaje se forma. Además, partiendo de los estudios de Raglan y Campbell, este recuento tiene la tarea de destacar los puntos en común que el relato de Magallanes comparte con los relatos de otros héroes. Asimismo, en el siguiente recuento de la vida de Magallanes dejaré de citar la fuente cuando el hecho sea una circunstancia fáctica verificable y más bien citaré al autor cuando la

4. Todo estudio posterior se basa en estas obras tempranas por lo que no he encontrado necesario incluirlos en la bibliografía. 
noticia de la vida de Magallanes sea una suposición, una opinión o tienda a ser un recuento exagerado de los hechos.

Poco se conoce sobre la temprana vida de Magallanes, incluso el lugar y fecha de su nacimiento son debatidos. Según Raglan, el inicio del héroe se da con las especiales circunstancias de su origen y/o su crianza, pues muchos de los héroes mitológicos son criados por padres adoptivos en un lugar lejano ${ }^{5}$. Este explorador satisface este prerrequisito: Magallanes es de estirpe noble y se cría lejos de sus padres, concretamente en la corte real donde primero sirve de paje a la reina Doña Leonor y después sirve como escudero al rey Don Manuel de Portugal.

Campbell advierte que es de esperar que los creadores de la leyenda tiendan a dotar al héroe con poderes extraordinarios desde el momento de su nacimiento ${ }^{6}$. Así, aunque poseemos escasos datos sobre los primeros años de Magallanes, varios autores se aventuran a formular suposiciones sobre el héroe. Por ejemplo, Queiroz Velloso, aunque no es un dato confirmado, presume que Magallanes llega a Lisboa con doce años (mínima edad establecida para ingresar en la corte portuguesa) y que ciertamente ya sabía leer y escribir. Según él, Magallanes iba a la corte a perfeccionarse en «latim, na equitação e no jôgo da espada a ambas mãos, que como a dança e boas maneiras constituiam a educaçao de um moço-fidalgo»?. Con ello, este autor no solo establece un inicio precoz en la educación de Magallanes, sino que además esboza en este navegante la figura del idóneo caballero perito tanto en la pluma como la espada.

Por otro lado, Barros Arana supone que, como otros hidalgos portugueses criados en la corte, este joven noble recibe durante sus primeros estudios «una educación mui cuidada bajo la protección y vigilancia del soberano» y se aventura a conjeturar que debido a su espíritu inquieto y emprendedor deseara buscar aventuras y se «ofreciera voluntariamente sus servicios para ir a militar en las apartadas regiones del Asia» ${ }^{8}$. Esta imagen del temprano ánimo emprendedor del joven Magallanes es compartida por otros autores, como Latino Coelho quien afirma que su ánimo varonil y aventurero se cansase de la vida de palacio en el que «Sentia-se porventura enclausurado o espirito d'aquelle que de nada menos se satisfez, que de navegar extensos mares desconhecidos e legar o seu nome aos fastos mais illustres da moderna geographia» ${ }^{9}$. Notamos que ambos autores lejos de limitarse a recontar una historia oficial llegan a aportar opiniones personales sobre el espíritu de este joven -inquieto, emprendedor - y a hacer afirmaciones en cuanto a su sentir -enclaustrado, insatisfecho. Igualmente, manifiestan que este personaje encarna desde su mocedad el espíritu del héroe aventurero interesado en dejar su nombre inscrito en la historia. Con ello, estos cronistas contribuyen a formar la historia - con $h$ minúscula- de Magallanes y se apartan de escribir Historia.

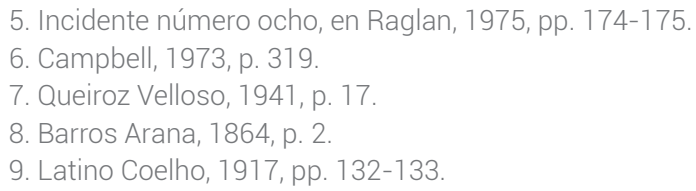


Magallanes crece en la corte portuguesa, en un ambiente colmado de noticias de descubrimientos y nuevas conquistas del imperio lusitano. Portugal florecía, además, como un centro de estudios y avances en las ciencias. La corte es para el joven Magallanes, según Lagôa, un lugar donde pudo «familiarizar-se com os eruditos componentes da celebrada "Junta dos Matemáticos" [...] com os membros das Casas da India e da Guiné [...] [e] os sábios eminentes da época» ${ }^{10}$. La aseveración de Lagôa resulta debatible si tenemos en consideración que la ocupación de Magallanes en la corte, primero paje y luego escudero, dudosamente le daría posibilidad de codearse con estas personalidades. Inclusive Anglería -uno de los críticos más asiduos del capitán portugués- afirma que Magallanes sabía del estrecho desde su infancia, cuando se entera en Portugal de la existencia de un estrecho, cuya entrada era difícil de encontrar ${ }^{11}$.

Si Barros Arana y Coelho conjeturan sobre el ánimo inquieto del navegante y dibujan a un Magallanes intranquilo y aventurero, Lagôa y Anglería aportan postulados sobre los posibles conocimientos náuticos, cartográficos y científicos que este personaje pudo haber tenido desde bastante joven e inclusive antes de que hubiese ejercido práctica en navegación.

Esta necesidad entre los historiadores de encontrar actos maravillosos en el héroe desde su temprana edad concuerda, según Campbell, con la opinión de que la heroicidad está predestinada, y abre el problema en cuanto a la biografía del personaje $^{12}$. Latino Coelho confirma esta noción al afirmar que Magallanes se sentía interiormente «predestinado para altas empresas e glorias immortaes» ${ }^{13}$.

Así, en lugar de aceptar a un mero ser humano con ánimo de superación, el carácter del héroe empieza a establecerse: un individuo virtuoso que tiene el valor y la convicción de llevar a cabo hazañas que benefician a la población en general y poseedor de un espíritu altruista que lo arrastra a actuar contra el mal y defender el bien, incluso sacrificando su propia vida o bienestar.

En 1505, Magallanes se embarca rumbo a África formando parte de la armada de Francisco de Almeida, iniciando así su experiencia y sus conocimientos de navegación. Durante su estadía en África y Asia, Magallanes participa en campañas, batallas y expediciones con sus compañeros. Nuevamente los autores distinguen al novato navegante de sus compañeros en su «cuidado particular de recoger y apuntar noticias referentes a la navegación de aquellos mares» ${ }^{14}$. Barros Arana no solo diferencia a este personaje de sus compañeros por su preocupación de observar y tomar nota de todo cuanto veía, sino que además relata un evento en el que Magallanes se distingue por su heroísmo cuando advierte una celada planeada por los malayos, da la voz de alarma y sin perder «su sangre fría en medio del conflicto, prestó oportunos auxilios a sus compatriotas [...], los que se salvaron de una

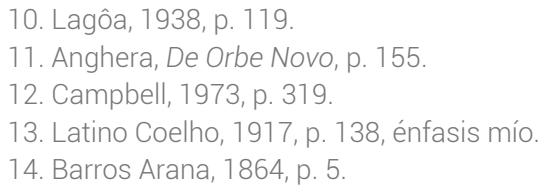


muerte segura» ${ }^{15}$. Notamos que el recuento fáctico de los hechos se entremezcla con la opinión de este autor sobre que el héroe no perdió su sangre fría y, de este modo, el juicio personal ayuda a construir la imagen del héroe intrépido e invencible ante la adversidad. Lagôa, por su parte, refiere otra oportunidad en que Magallanes se destaca durante un suceso ocurrido cuando cierto junco, que los portugueses habían aprisionado, empieza a hundirse. Magallanes no solo protesta en no abandonarlo, como el capitán había dispuesto, sino que además dirige las operaciones de salvamiento de los hombres que habían quedado a bordo ${ }^{16}$.

Estos son algunos relatos de los distinguidos actos del joven Magallanes embelesados con juicios de valor y los criterios de los historiadores de la época. Los autores hacen un esfuerzo en rescatar y subrayar las grandiosas hazañas que este personaje realizó durante sus años mozos. Constatamos que hay un intento en común de distinguir el arrojo, valentía y dignidad del joven navegante. Tanto los historiadores españoles como los portugueses le adjudican un carácter resuelto, incluidos los cronistas portugueses quinientistas - quienes se ensañaron contra la deslealtad de este navegante hacia la corona portuguesa- relatan episodios memorables. Así, se van tejiendo los extraordinarios actos de Fernando de Magallanes quien desde sus años mozos va demostrando no solo su valor, sino también su nobleza. De esta manera, el personaje histórico va desvaneciéndose y el héroe mítico empieza a construirse.

La historia del navegante portugués en tierras foráneas no solo evidencia acciones heroicas. El conocimiento de ese mundo parece perfilar su interés de proseguir con la aventura. Durante su estadía en Malaca, Fernando de Magallanes participa en un viaje de exploración para reconocer las famosas Molucas, a las cuales no llegan. Tal expedición, según los autores, despierta en él el deseo de encontrar el país de las especias, apuntando que de ese modo comienza su llamado a la aventura. Tras ese viaje, se dedica particularmente «al estudio teórico de la cosmografía y de la náutica, como igualmente a la composición de una obra de los países que había visitado» ${ }^{17}$.

Magallanes regresa a Portugal lesionado de una pierna por haber sido herido en batalla. Una vez en Lisboa, acude al rey don Manuel de Portugal con ciertos requerimientos en reconocimiento a sus servicios, pero el rey rechaza sus pedidos. Viéndose desfavorecido y sintiéndose agraviado pide al rey «licença pera hir viuer com quem the fizesse mercê, em que alcançasse mais dita que com elle. EIRey Ihe disse que fizesse o que quigesse; polo que lhe quis beijar a mão, que lhe EIRey nom quis dar» ${ }^{18}$. Correa parece mezclar este hecho histórico de pedir licencia a su rey para continuar con su afán aventurero con un suceso anecdótico que, más que histórico, parece querer enfatizar el respeto que Magallanes demostró al rey -con el beso en la mano- y la displicencia que el rey de Portugal manifestó a este navegante con su rechazo.

\footnotetext{
15. Barros Arana, 1864, pp. 5-6.

16. Lagôa, 1938, p. 132.

17. Barros Arana, 1864, p. 10.

18. Correa, 1860, p. 626.
} 
El héroe había caído en desgracia. Un conjunto de circunstancias dirigían el ánimo del rey don Manuel en contra de este caballero: circulaban calumnias de que Magallanes había vendido cierto ganado que no le pertenecía, también acusaciones de que su cojera era fingida y, además, escribieron al rey quejándose de que Magallanes había regresado a Portugal sin permiso. Al navegante portugués se le presentaban dos caminos: conformarse, y así ser fiel a la patria, o seguir su sueño contestando el llamado a la aventura ${ }^{19}$. En el espíritu de Magallanes prevalece el llamado a la aventura, llamado que domina las acciones del héroe.

Fernando de Magallanes decide abandonar Portugal, y no solo pide permiso a su rey de abandonar su patria, sino que, además, según las versiones españolas, se desnaturaliza por actos públicos ${ }^{20}$. Este no es un hecho comprobado, es más, fue debatido por las versiones portuguesas ${ }^{21}$. Con ello, confirmamos que los autores españoles siguen tejiendo el mito-historia del héroe con el deseo no solo de seguir ensalzando la figura de Magallanes que se desnaturaliza «como cumplía a un hidalgo del siglo XV|», sino que, además, con esta noticia intentan ratificar esta gloria única y exclusivamente para el reino español, al tratar de establecer que Magallanes ya no era portugués cuando se entregó a su gesta.

El llamado a la aventura llega al héroe de distintas maneras: bien por una orden directa, bien a través de un sueño o por la necesidad de salvar el honor ${ }^{22}$. En casos, como el de Magallanes, el héroe se da cuenta de que a la sociedad se le niega algo y, por tanto, decide ir en su búsqueda con el fin de ganar tales derechos para el pueblo. Este sería el caso del comercio de las especias monopolizado por los portugueses, derecho que se negaba a España.

Magallanes, por tanto, decide pasar a Castilla donde trata de convencer al rey Carlos $\mathrm{V}$ que las Molucas quedan dentro de su territorio y que él sabe de un paso hacia esos mares ${ }^{23}$. Los planes del navegante portugués le parecen al Emperador y a los miembros de su Consejo «cosa muy dificultosa y de vanidad [...] [dicho] pasaje se había buscado con mucha diligencia y con grandes trabajos, mas nunca se había podido hallar» ${ }^{24}$. Transilvano proyecta el arrojo del héroe en la figura de Magallanes, quien no presenta temor en ir a descubrir las islas Molucas, «cosa muy incierta y en que se ofrecerían grandísimos peligros» ${ }^{25}$. Los autores distinguen, pues, la determi-

19. El llamado a la aventura es una de las etapas del mito del héroe. Ver «The Call to Adventure» en Campbell, 1973, pp. 49-58.

20. Barros Arana (1864, p. 13) dice: «Antes de dejar su patria, Magallanes quiso desnaturalizarse, como cumplía a un hidalgo del siglo XVI. Hízolo, en efecto, por actos públicos, y con toda solemnidad, para quedar libre de ofrecer sus servicios a quien mejor quisiera». Aganduru, por su lado, afirma que se desnaturaliza ante escribano público (Historia general de las islas occidentales..., p. 16).

21. Queiroz Velloso (1941, p. 31) desmiente fervientemente la sugerencia de que Magallanes se desnaturalizó públicamente.

22. Campbell, 1973, pp. 49-58.

23. Ruy Falero, cosmógrafo y socio de Magallanes, participó en todas las gestiones y obtuvo los mismos derechos para participar en dicha expedición, pero enfermó y se quedó en España.

24. Transilvano, Relación..., pp. 263-264.

25. Transilvano, Relación..., p. 264. 
nación del carácter heroico de Magallanes y su tenacidad de no detenerse ante lo desconocido ni ante las múltiples dificultades del pretendido camino.

Magallanes está ante el primer umbral de su partida, paso que el héroe debe franquear. Este umbral separa las comodidades del hogar y la experiencia conocida de un nuevo mundo de aventura lleno de misterio y peligro ${ }^{26}$. La persona común está satisfecha, incluso orgullosa, de permanecer dentro de los límites establecidos, y la creencia popular le proporciona suficientes razones para inclusive temer dar el primer paso hacia lo inexplorado27. Pero el héroe, en este caso Magallanes, tiene el valor y la convicción de llevar a cabo su hazaña y de hacer frente a lo desconocido.

Como tantos otros héroes, Magallanes encuentra en su camino a una figura protectora que constituirá el poder benigno de su destino ${ }^{28}$. En el caso del navegante portugués, son tres personajes los que contribuyen en la ejecución de su plan: Juan de Aranda, factor de la Casa de Contratación, uno de los primeros en prestar atención e interesarse por su proyecto; Juan Rodríguez de Fonseca, obispo de Burgos, quien se convierte en su protector; y Cristóbal del Haro. Este último, si bien, no entrega a Magallanes una ayuda sobrenatural, le ofrece algo mejor: dinero. Cristóbal del Haro se compromete a financiar la misión y su interés en la empresa de Magallanes, en cierta manera, acelera la toma de decisión.

No obstante, el rey español insiste en saber por dónde viajaría Magallanes. «El futuro descubridor dijo entonces que en la tesorería del rey de Portugal había visto una carta de navegar... [de] Martín Behaim, en que estaba señalada una comunicación entre ambos mares» ${ }^{29}$. La mención de la carta de marear de Martín de Bohemia ${ }^{30}$, cosmógrafo portugués, actúa como la poción mágica para su aventura. Finalmente, Carlos $V$, reconociendo el futuro beneficio económico que podría devenir de esta empresa, decide cargar con el costo de la expedición proveyendo y abasteciendo cinco navíos para la jornada.

Fernando de Magallanes ha dado el paso necesario para emprender su empresa, está a punto de cruzar el primer umbral de su partida y se ha convertido en el guardián del umbral ${ }^{31}$, ocupando un lugar entre el mundo conocido y lo desconocido. Mas, como custodio del umbral, afronta una nueva serie de pruebas y tribulaciones. Se enfrenta a los celos de otros navegantes que pretendían tal empresa; a los obstáculos que le impone la corona portuguesa que trata de desacreditarlo ante el rey español; también se enfrenta a los recelos de los castellanos quienes no

26. Sobre el primer umbral ver «The Crossing of the First Threshold» en Campbell, 1973, pp. 77-89

27. Campbell, 1973, p. 78.

28. Sobre el protector benigno y la ayuda sobrenatural ver «Supernatural Aid» en Campbell, 1973, pp. 69-76.

29. Barros Arana, 1864, p. 30

30. La existencia y la exactitud de dicho mapa son muy debatidas. Sobre este mapa y los conocimientos geográficos de la época consultar Merino, 1917, pp. 11-26.

31. Sobre el guardián del umbral (threshold guardian) ver «The Crossing of the First Threshold» en Campbell, 1973, pp. 77-89. 
tienen a bien embarcarse bajo el mando de un extranjero, por lo cual alista a muchos extranjeros entre su tripulación ${ }^{32}$. Ante todo esto, los preparativos se dilatan.

El 20 de septiembre de 151933, comienza la aventura del héroe quien, partiendo de Sanlúcar, da el primer paso más allá del velo de lo conocido hacia lo desconocido. Con ello, empieza el camino de su odisea en la que el héroe se enfrentará a una serie de aventuras. Al igual que las travesías náuticas de los héroes griegos quienes se encontraron con peligros y aventuras, en el pasaje a este mundo desconocido, Magallanes y sus hombres descubren un universo extraño donde encuentran naciones de caníbales, de gigantes, de guerreros flecheros y de ladrones, entre otras. Presencian sucesos sorprendentes como fuegos nocturnos en la tierra y eclipses solares. Encuentran un recinto con doscientas sepulturas en un lugar donde no hay señales de habitantes. Se topan con un cementerio de ballenas, también con una isla con un número tan grande de lobos y patos marinos -estos últimos, no eran más que pingüinos- que espantan a la tripulación.

Tal como en la odisea de Ulises, estos navegantes encuentran distintas naciones con reglas y maneras diferentes, de usos no vistos ni oídos, y que en muchos casos tratan de buscar interpretaciones entre sus conocimientos, como cuando comparan a los nativos excesivamente ladrones con los gitanos. Estos navegantes se encuentran ante el nuevo espacio americano donde el imaginario europeo tratará de encontrar explicación a seres y lugares legendarios ${ }^{34}$.

Magallanes y sus hombres encuentran grupos que tratan de evitar como es el caso de los «indios flecheros» ${ }^{35}$, así como naciones amigas a las que procuran cristianizar, como el grupo de gigantes a quienes denominan patagones. Además, en su camino obtienen informes sobre naciones y hechos fabulosos que por la premura de tiempo tienen que evitar, como el país de los pigmeos de orejas tan grandes que les servían para cubrirse al dormir. Cuanto más se acercan a la tierra prometida advierten más riqueza y esplendor. Así, llegan a reinos de gran pompa y majestuosidad, donde montan elefantes, usan deslumbrantes joyas, tienen cientos de mujeres e hijos y conocen a un rey al que solamente se le puede hablar a través de una cerbatana ${ }^{36}$. Comprobamos que no solo la figura del héroe se ha ido delineando, sino que los autores, además, trazan el espacio para la aventura del héroe: un mundo desconocido con naciones inéditas y personajes fabulosos.

32. Entre los tripulantes iban «veinticuatro portugueses, veintidós italianos [...], veintiún franceses, cinco flamencos, tres griegos, dos alemanes y un inglés» (en Merino, 1917, p. 28). Así, pues, cerca de una tercera parte de la tripulación de Magallanes la conformaban extranjeros.

33. Existe entre los autores divergencia en cuanto a la fecha de partida, parece deberse a que el $10 \mathrm{de}$ agosto de 1519 las naves soltaron sus amarras, pero el 20 de septiembre levaron anclas. Las fechas son siempre en agosto o septiembre de 1519, solo un autor afirma que partieron en febrero; ver Aganduru, Historia general de las islas occidentales..., p. 19.

34. Ver Baraibar, 2011, pp. 9-30.

35. Herrera, Historia general de los hechos de los castellanos..., p. 300.

36. El recuento más descriptivo y detallado de todos los territorios visitados se encuentra en el diario de viaje de Francisco Antonio Pigafetta, Primer viaje en torno del globo. 
Desde la partida, el camino del héroe es una ruta de aventuras pero sobre todo es un pasaje de tareas y pruebas. En ese nuevo mundo de aventura, el héroe debe enfrentar una serie de retos y pruebas que forman parte de su iniciación y lo ayudan a mejorar su carácter y habilidades convirtiéndose así en un ser más autosuficien$t^{37}$. El ingenio del héroe, en muchos casos, guía y resguarda a sus hombres como, por ejemplo, cuando tratan de prender a los patagones para llevarlos a Castilla y les resulta sumamente difícil. Magallanes se vale de la treta de llenarles las manos con un gran número de regalos y luego ofrecerles grillos de hierro. Cuando los patagones no logran cargarlos con las manos, el capitán les propone sujetárselos a los tobillos y así los logran encadenar ${ }^{38}$. En otra ocasión también se hace manifiesta su astucia cuando, a fin de no ser atacados por los nativos, Magallanes los atemoriza demostrando y exagerando el poder de su armada ${ }^{39}$. Añadiéndose al espíritu aventurero de Magallanes, a su arrojo y valentía, los autores perfilan ahora su ingeniosidad engrandeciendo aún más su mito-historia.

Magallanes y los suyos tienen que persistir ante la incertidumbre del camino y sobreponerse al miedo, padecer hambre, necesidades y enfermedades. Al mismo tiempo, tienen que enfrentar las inclemencias del clima, subsistiendo un inaguantable frío y las terribles e interminables tempestades. Ese camino de retos que encuentra el héroe, comúnmente, no está completo hasta que el héroe sobreviene un desafío muy importante a lo largo de su viaje. Campbell explica que cuando el héroe llega al punto más bajo de su círculo mitológico, este pasa por una prueba suprema y, con ello, gana su recompensa. Con esta prueba el héroe logrará una expansión de su conciencia ${ }^{40}$. La prueba suprema que tiene que superar Magallanes es el motín de sus hombres.

Encontrándose en la Bahía de San Julián, Magallanes determina invernar ahí y racionar las provisiones. El descontento es general en cuanto al «arreglo en la distribución de los comestibles, y sobre todo impaciente por la incertidumbre del éxito de la empresa» ${ }^{41}$. Le demandan regresar a España y darse por satisfecho de haber llegado hasta donde nadie antes se había atrevido ${ }^{42}$. Transilvano resalta que el descontento era principalmente entre los castellanos ${ }^{43}$. El capitán general trata de convencer a su gente con diversos razonamientos $y$, sobre todo, les recuerda el valor de los castellanos. Según las fuentes históricas, Magallanes pronuncia un discurso para motivar a sus hombres. Esta arenga, en algunas versiones, es simplemente mencionada, es citada por ciertos autores y entre otros construida con gran detalle, como en el caso de Aganduru. El hecho de que un historiador pueda citar una arenga con tanto detalle y presentarla verbatim es bastante cuestionable

37. Ver «The Road of Trials» en Campbell, 1973, pp. 97-108.

38. Pigafetta, Primer viaje en torno del globo, p. 57.

39. Pigafetta, Primer viaje en torno del globo, p. 85

40. Campbell, 1973, p. 246

41. Ortega, Resumen histórico del primer viaje..., p. 10.

42. Ver Herrera, Historia general de los hechos de los castellanos..., p. 297; Transilvano, Relación..., p. 270; Ortega, Resumen histórico del primer viaje..., p. 10; y López de Gómara, Historia general de las Indias, pp. 213-226.

43. Transilvano, Relación..., pp. 272-273 
y lo dejo al criterio del lector, para lo cual transcribo la arenga a pie de página ${ }^{44}$. En mi opinión, esta arenga es otra construcción del héroe mítico, que en este caso se glorifica no mediante sus acciones, sino a través de su don de palabra.

Finalmente, imponiendo su don de mando, decide quedarse ahí, pues, según anuncian los cronistas, había resuelto salir con su designio o morir en su demanda ${ }^{45}$. El descontento continúa y sus hombres se sublevan. Sin embargo, Magallanes, considerando «que era mejor remedio la temeridad que el sufrimiento, con diligencia mandó armar toda la gente de la Capitana ${ }^{46}$. El capitán general actúa con presteza, empleando al mismo tiempo astucia y fuerza, y envía a sus hombres armados secretamente a la nave Vitoria con una carta para el capitán Luis de Mendoza. Mientras este la leía, el

alguacil Espinosa dio una puñalada al dicho Mendoza por el garguero, y otro marinero una cuchillada en la cabeza en el mismo instante, de que cayó muerto [...] [luego] envió el dicho Magallanes en un batel con Duarte Barbosa [...] quince hombres armados, y entraron en la dicha nao Vitoria, e la señorearon, y alzaron la bandera ${ }^{47}$.

44. «Confieso, señores castellanos, que los trabajos que se han pasado, desde que nos apartamos de nuestra España, han sido grandes, surcando inciertos mares, descubriendo varias tierras en regiones escondidas e incultas, contradiciendo nuestros altos pensamientos la crueldad de tan remoto é innavegable mar y la ferocidad de los contrarios vientos, que parece defienden que no entremos por la puerta del Estrecho que buscamos; señales evidentes de la riqueza que el Mar del Sur nos tiene aparejada. Gran empresa acometemos, pero mayores son vuestros bríos, y no hay dificultades que no se rindan a la perseverancia y cedan al trabajo; si no hubiera Sagunto ni Italia no hubiera sido famoso Aníbal, a quien los Alpes humillaron sus cabezas. Cartago y Numancia eternizaron a los dos Scipiones. El magno Alejandro pudo, atropellando dificultades, llegar y ver la mesa del sol, y antes, por los desiertos hirvios, el gran Templo de Menón. Catón Uticense, a pesar de los ardores de África, pasó sus arenales, y vio el fin glorioso de su jornada. Y Julio César, vencido de una tormenta en les mares británicos, a pesar de la fortuna y tiempos, acometió segunda vez sus feroces olas, y rompiendo montes de agua llegó a beber las dulces de Albión domando los britanos. Y si retrocedemos por las edades hallaremos constante ejemplo en la perseverancia de los griegos sobre Troya, donde, a vista de sus muros, sufrieron con ánimo constante las nieves y escarchas de diez inviernos y los calores de diez veranos, con las incomodidades que a tanto número de gente en extranjera y enemiga tierra apretaban. No ha diez años, valerosos soldados, que acometemos este gran continente de tierra, deseando ver de los muros de estos montes algún portillo para entrar a la deseada Troya, ni en valor, ni en ánimo somos inferiores a los griegos, y si mayor empresa acometemos que ellos, es por la superioridad que los tenemos. El Estrecho no puede estar lejos donde vuestro ánimo y valor está tan cerca. En este puerto podremos sufrir los rigores de este invierno y adrezar nuestros navíos despacio para que podamos después en el verano, por la puerta que buscamos, salir al espacioso Mar del Sur. Confío, señores de vuestro invencible ánimo, que cuando a mí me faltase, le había de hallar en vosotros como en valientes castellanos» (en Aganduru, Historia general de las islas occidentales..., pp. 28-29).

45. Ver Barros Arana, 1864, p. 62; Herrera, Historia general de los hechos de los castellanos..., p. 297; Transilvano, Relación..., p. 271; Fernández de Navarrete, Viaje de Magallanes..., p. 41; Fernández de Oviedo, Historia general y natural de las Indias, p. 11

46. Herrera, Historia general de los hechos de los castellanos..., p. 298.

47. López de Recalde, «Carta del contador Juan López de Recalde al Obispo de Burgos», p. 167. 
Con ello, logra sofocar rápidamente la insurrección. Prontamente, ajusticia a los participantes condenando a pena de muerte a Gaspar de Quesada, y sentenciando a dejar desterrados en aquellas costas a Juan de Cartagena y a un fraile involucrado, Pedro Sánchez de la Reina.

El hecho histórico de que Magallanes logró sofocar la rebelión y que, obviamente, para ello tuvo que actuar con presteza y osadía no se pone en duda. Lo que es necesario resaltar es que en el recuento de este suceso los autores contribuyen con dictámenes personales resaltando los sentimientos y los pensamientos del navegante y, con ello, conducen la opinión del lector en cuanto a la temeridad y determinación del héroe.

Finalizado el invierno, habiendo salido triunfante y vencedor de la prueba suprema, Magallanes está listo para recibir su recompensa: el estrecho. El capitán continúa la búsqueda del paso anhelado haciendo reconocimiento del área. Durante estos reconocimientos zozobra una nave que pierde el control durante un temporal, otra abandona la expedición y da marcha atrás. Con solo tres naves restantes y venciendo increíbles dificultades halla el canal que comunica los dos mares. Demora cerca de un mes en navegar el estrecho -algunos autores sostienen que más de un mes- pues toma tiempo en las excursiones de reconocimiento, como en esperar a la cuarta nave que nunca llegó, pues se hallaba de retorno a España.

El capitán había logrado abrirse paso para conseguir el tan deseado don: el paso a las especias de las Molucas. Esto es lo que Campbell denomina el boon, es decir, la meta o bendición de la jornada del héroe, que es la finalidad de su peregrinación. El héroe se encuentra ahora listo para tomar posesión de su recompensa y continuar el camino de regreso a casa. Sin embargo, el camino de regreso del héroe en muchas ocasiones involucra más retos y barreras, como ocurrirá con este aventurero. Su viaje de regreso es más largo de lo esperado, porque desconocía la inmensidad del Océano Pacífico en el que navegaron cerca de cuarenta días sin encontrar tierra, pasando hambre y padeciendo enfermedades y muertes. Cuando finalmente topan con tierra, encuentran unas islas inhabitadas y sin alimentos.

Un poco más adelante descubren algunas islas más ricas y llegan a la isla de Cebú 48 . Allí traban amistad con el rey y sus pobladores, que consienten en formar alianza con Castilla y a quienes logran cristianizar. Según Pastells afirma, la gloria de Magallanes estaba en su cumbre:

... dejaba su nombre inmortalizado en el Estrecho; había surcado felizmente los inacabables abismos del Océano; a dos pasos de las Malucas, blanco final de la expedición, hallaba indios amigos que lo surtían de víveres y le brindaban su apoyo; casi sin trabajo ni diligencia por su parte, veía el pendón de su Rey ondear en nuevas islas y en mares, cuya hegemonía se abrogaba hasta entonces Portugal ${ }^{49}$.

Sin embargo, Magallanes resuelve combatir a los pobladores de Mactán, la isla vecina, quienes no se avienen a rendir vasallaje al rey de Cebú. En este punto, 
Fernando de Magallanes pierde el favor de los dioses ${ }^{50}$, pues la rueda de la fortuna torna para este héroe. El navegante portugués no regresará a casa -y como Aquiles no logra su nostos - pues en dicha batalla pierde la vida encontrando una muerte penosa.

El capitán general que solo contaba con una limitada escuadra de hombres se enfrenta a una armada de miles de nativos. El número de las fuerzas de Magallanes y de los enemigos varía de autor a autor. Mientras la armada española es, según la versión, entre unos cuarenta a sesenta hombres, los enemigos son alrededor de mil quinientos, a veces, hasta seis mil hombres. Una vez más, encontramos el deseo común entre los autores de ensalzar las hazañas del héroe, en esta oportunidad tendiendo a la exageración.

Pelean con tesón, pero, debido a la diferencia en número, las fuerzas españolas tienen que retroceder. Por lo cual, Magallanes ordena la retirada y

... quedóse atrás para proteger a los otros, con seis u ocho hombres [...] viéndole los enemigos casi abandonado, arremetieron a él con más furia, dirigiéndole los golpes a las piernas, que estaban desarmadas. Una piedra le derribó la celada, y en tal estado... un indio le hirió en la frente con una lanza de bambú; revolviose contra él Magallanes, y lo atravesó con la suya, que no pudo retirar. Quiso entonces sacar la espada, pero le fue imposible desenvainarla, por tener el brazo derecho gravemente herido [...] abalanzáronse sobre él, diéronle una cuchillada con un alfanje en la pierna izquierda, y no pudiendo tenerse en pie, cayó de bruces, y allí lo remataron a golpes y lanzadas ${ }^{51}$.

En la cita anterior, apreciamos que Magallanes, como tantos otros héroes, experimenta la prueba final: una muerte violenta. Mucho se ha escrito sobre su muerte ${ }^{52}$, los autores, en mayor o menor detalle, describen una contienda en la que Magallanes es siempre el centro de la agresión de los enemigos, donde el héroe no disminuye su tesón en la batalla y no se da por vencido hasta su último aliento. Fernando de Magallanes muere en la isla de Mactán, el 27 de abril de 1521, dejando a su gente desconsolada porque «fue grandísimo el llanto de la gente, porque querían bien a su capitán, y tenían dél tan gran conceto» ${ }^{53}$.

Los españoles, vista su desventaja en número, no logran recuperar el cuerpo de su capitán en combate, no obstante ofrecen a los mactaneses

la cantidad que pidieran de aquellas mercaderías que llevaban en sus naves. Los vencedores, enorgullecidos con tan reñido y completo triunfo, respondieron que nada podría reducirlos a deshacerse del cadáver de un hombre como el jefe de los castellanos, y que ellos querían guardarlo como un monumento de victoria ${ }^{54}$.

50. La pérdida del favor de los dioses es uno de los 22 incidentes de la lista de Raglan, 1975, p. 17. 51. Pastells, 1920, pp. 103-104.

52. Una recopilación de las diferentes versiones de su muerte en Ibáñez Cerdá, 1975, pp. 411-434.

53. Herrera, Historia general de los hechos de los castellanos..., p. 8.

54. Barros Arana, 1864, pp. 119-120. 
No logran, pues, «redimir su cuerpo para darle honrosa sepultura»55. La necesidad de conservar el cuerpo resulta de la exigencia de darle un adecuado entierro católico, pero desde el punto de vista del héroe el cuerpo es necesario por el hecho de poseer la tumba del héroe ${ }^{56}$-este tema merece otro estudio ${ }^{57}$. Ahora, si bien no encontramos una lucha encarnizada en el hecho de obtener el cuerpo de Magallanes, lo interesante es el anhelo de recuperarlo, que resulta ser otro marcador de similitud con el mito del héroe. Es importante reconocer la misma mención del hecho de que traten de recuperar el cuerpo del héroe y de que los enemigos deseen retenerlo como trofeo.

Aquí acaba el recorrido de Magallanes pero no su gesta. Sus hombres continúan con su misión y, enfrentando más muertes, trabas y peligros llegan a las Molucas. En el camino de regreso necesitan quemar una de las naves por falta de tripulantes y otra debe quedarse con su tripulación por estar muy dañada y no soportar el viaje. Tres años después de su partida, el 6 de septiembre de 1522, Sebastián Elcano arriba a Sanlúcar de Barrameda al mando de la nao Victoria con tan solo 18 tripulantes, pero con sus bodegas llenas de productos de las Islas Molucas -el don o regalo que traen de regreso al mundo ordinario.

Elcano fue reconocido por su logro por el rey de España ${ }^{58}$ y sus coetáneos. La noticia de la primera vuelta al globo se expandió rápidamente por toda Europa. Sin embargo, en lo que atañe a esta gesta, Elcano solo ocupa el lugar del héroe secuaz. Al igual que Aquiles quien, sin llegar a conquistar Troya (llión), es el héroe de La Iliada, la historia del paso austral y la primera vuelta al mundo pertenece a Magallanes. Si bien Elcano es quien regresa a España, él no será el héroe de esta aventura. Elcano sirve solo como una de las piezas de la hazaña y de la historia que escribió Magallanes. Como afirma Oviedo, no obstante el capitán mayor «no llegó a las islas de los Malucos y Especiería, este loor a solo Magallanes se le debe, y a él se atribuye este grand viaje y descubrimiento» ${ }^{59}$.

55. Ortega, Resumen histórico del primer viaje..., p. 29.

56. Martin Nilsson (1925, p. 104) apunta al poder de los restos del héroe. Afirma que el culto al héroe yace en la creencia de la continuidad de la existencia corporal de un hombre poderoso después de su muerte. El culto al héroe es en el fondo un culto a hombres notables que han muerto, cuyo poder se extiende y aplica a la totalidad de su tierra y a todos sus habitantes.

57. Resulta interesante apuntar que, si bien los castellanos no obtuvieron el cuerpo de su capitán, Magallanes goza de un lugar donde se consagra la memoria de sus restos. Este hecho parece haber causado cierta confusión de que el cuerpo de Magallanes estaba sepultado en las Filipinas porque a principios del siglo XX se incitó en España «una campaña cuyo objeto principal es traer a la Península los restos de Magallanes» (Merino, 1917, p. 34). El tema de la tumba del héroe resultará en una investigación separada.

58. «El emperador premió generosamente los servicios de Juan Sebastián de Elcano. Colmólo de honores y distinciones, concedióle una pensión anual de quinientos ducados de oro, autorización para llevar siempre dos hombres armados para guarda de su persona, y un escudo de armas cuyos cuarteles aludían a varias circunstancias del viaje y cuya cimera era un mundo con esta inscripción: Primus circundedisti me» (Barros Arana, 1864, p. 131).

59. Fernández de Oviedo, Historia general y natural de las Indias, p. 34. 
Mientras Elcano logra su nostos (su regreso a casa), Magallanes obtiene el vellocino de oro (el buscado y anhelado paso), con lo cual su nombre queda inmortalizado en el estrecho. No se niega el logro de Elcano y, como el logro de Ulises con su astuta treta para abrir las puertas de Troya, su hazaña pasa a los anales de la historia. Sin embargo, la expedición que resultó en la primera vuelta al mundo llevará por siempre el nombre de Magallanes. Él es el héroe primario y quien gana la gloria de haber abierto el paso a los españoles para la posesión del don o regalo que beneficiará y mejorará el mundo -en este caso España.

Resumiendo, entre las similitudes que la historia de Magallanes comparte con las historias de los héroes míticos, según las clasificaciones de Raglan y Campbell, están: las especiales circunstancias de su crianza; la llamada a la aventura; el protector benigno y la ayuda sobrenatural; el cruce del primer umbral y la partida a lo desconocido; la serie de tareas y pruebas; la prueba suprema y su recompensa; la obtención del don o regalo; la pérdida del favor de los dioses; y una muerte penosa.

Como advierte Campbell, la biografía del hombre histórico no es relevante para el estudio de su mito. Por ello hemos relatado el mito-historia de Magallanes, pues, según observa Kirk, la historia puede convertirse en mito en casi cualquier etapa ${ }^{60}$.

\section{CONSIDERACIONES FINALES}

Constatamos, tal como anuncia Campbell, que si los hechos de una figura histórica real lo proclaman héroe, los constructores de su leyenda inventarán para él aventuras apropiadas ${ }^{61}$. En muchos casos, no se puede verificar qué actos y eventos atribuidos a Magallanes fueron históricos, no hay comunión ni siquiera en cuanto a las fechas más memorables, o al número de tripulantes que se embarcaron ni siquiera de los que regresaron. Comprobamos que los eventos se narran a veces en un orden diferente, en ocasiones con omisiones y, en muchos casos, con pronunciadas exageraciones. Asimismo, advertimos que los autores sazonan sus narraciones con dictámenes y opiniones personales, e incluyen pensamientos y sentimientos del héroe. Con todo ello, cada uno de los historiadores de Magallanes contribuye en desvestir al personaje histórico y vestir al personaje mítico.

Este no es el lugar para comprobar la veracidad de uno u otro historiador, simplemente, el intento es demostrar que en conjunto participan en trazar una imagen particular de Fernando de Magallanes. Es, justamente, en lo no histórico de sus relatos en lo que debemos enfocarnos. Estos relatos lejos de intentar presentar un objetivismo fáctico, presentan narraciones apasionadas e interesadas. Los autores, en ocasiones, quieren halagar al individuo y en otras envilecerlo, como es el caso de los cronistas portugueses que lo acusan de traidor a la patria. También, entre aquellos que escribían para España, hay quienes imputan la actuación de Magallanes en cuanto al castigo de los amotinados - por ejemplo, Anglería y Aganduru62.

62. Aganduru, Historia general de las islas occidentales..., pp. 1-69. 
No todos están a favor del capitán portugués y no solo esbozan sus cualidades, también apuntan sus defectos. En todo caso, lo que resalta de estas narraciones es que Magallanes, como otros héroes, tiene una gama de atributos y debilidades, su historia satisface el requisito del sufrimiento que soportan los héroes y, sobre todo, cumple una de las características fundamentales del héroe: ser extremo.

Esta relectura del mito-historia de Magallanes ha entremezclado adrede las versiones de los historiadores a través de los siglos -específicamente del siglo $\mathrm{XVI}$ al XX- pues es de la suma de ellas que la noción colectiva de este personaje se forma. No pongo en duda que historiadores coetáneos y futuros tratarán de revisar datos y corregir errores en un intento de redimir la versión del hombre histórico. Sin embargo, el conocimiento comunal de esta historia ya está formado y el mito de este personaje está instaurado en la conciencia colectiva y dudosamente será corregido.

Considero que una lectura de cualquiera de los héroes de la conquista traerá un resultado similar que confirma que el mito del héroe -afincado en las conciencias - difiere del relato del hombre histórico. Campbell advierte que no se debe confundir la historia mítica del héroe con la del hombre histórico, aunque comparten el mismo nombre, en realidad son personas muy diferentes. La persona histórica una vez heroizada tiende a crear su propio mito. El mito del héroe que con el tiempo se desarrolla, amplia y evoluciona es lo que interesa, porque es a través de su mito que el mensaje se trasmite. Por tanto, Magallanes el hombre histórico ha desaparecido y es su mito lo que prevalece.

\section{BibliografíA}

Aganduru Moriz, Fray Rodrigo de, Historia general de las islas occidentales a la Asia adyacentes, llamadas Filipinas, en Martín Fernández de Navarrete, Colección de documentos inéditos para la historia de España, tomo LXXVIII, Madrid, Imprenta de Miguel Ginesta, 1882, pp. 1-69.

Anghera, Peter Martyr, De Orbe Novo, vol. II, trad. Francis Augustus MacNutt, New York, The Knickerbocker Press, 1912, pp. 151-171.

Argensola, Bartolomé Leonardo de, Conquista de las Islas Malucas, Zaragoza, Imprenta del Hospicio Provincial, 1891.

Baraibar, Álvaro, «La Naturaleza en el discurso indiano: la construcción de un espacio de experiencia americano», en Tierras prometidas. De la colonia a la independencia, ed. Bernat Castany et al., Bellaterra, Centro para la Edición de los Clásicos Españoles, 2011, pp. 9-30.

Barros, João de, Da Asia, Decada III, Parte I, Lisboa, Na Regia Officina Typografica, 1777.

Barros Arana, Diego, Vida y viajes de Hernando de Magallanes, Santiago de Chile, Imprenta Nacional, 1864. 
Campbell, Joseph, The Hero with a Thousand Faces, Princeton, Princeton University Press, 1973 [1949].

Correa, Gaspar, Lendas da India, tomo II, parte I, Lisboa, Typographia da Academia Real das Sciencias, 1860.

Correa, Gaspar, Lendas da India, tomo II, parte II, Lisboa, Typographia da Academia Real das Sciencias, 1861.

Elcano, Juan Sebastián, «Carta de Juan Sebastián del Cano al Emperador dándole breve relación de su viaje en la armada de Magallanes y de su regreso en la nao "Vitoria"», en José Toribio Medina, El descubrimiento del Océano Pacífico: Fernando de Magallanes y sus compañeros. Documentos. Anexo a la Memoria Universitaria, Santiago de Chile, Imprenta Elzeviriana, 1920, pp. 291-294.

Fernández de Navarrete, Martín, Viaje de Magallanes y de Sebastián de Elcano alrededor del mundo, Buenos Aires, Emecé Editores, 1944.

Fernández de Oviedo, Gonzalo, Historia general y natural de las Indias, islas y tierra firme del mar océano, tomo II, Madrid, Real Academia de la Historia, 1852.

Herrera, Antonio de, Historia general de los hechos de los castellanos en las Islas y tierra firme del Mar Océano, Decada Segunda, Libros IV y IX, Madrid, Imprenta Real, $1601-1615$.

|báñez Cerdá, José, «La muerte de Magallanes», en A viagem de Fernão de Magalhães e a questão das Molucas. Actas do II Colóquio Luso-Espanhol de história ultramarina, ed. A. Teixeira da Mota, Lisboa, Junta de Investigações Científicas do Ultramar, 1975, pp. 411-434.

Kirk, Geoffrey S., «The Qualities of Greek Myths», en Myth. Its Meaning and Functions in Ancient and Other Cultures, Berkeley, University of California Press, 1984, pp. $172-251$

Lagôa, Visconde de, Fernão de Magalhãis (a sua vida e a sua viagem), Livro I, Lisboa, Seara Nova, 1938.

Latino Coelho, José Maria, Fernão de Magalhães, Lisboa, Editores Santos \& Vieira, 1917.

Las Casas, Bartolomé de, Historia de las Indias, Libro III, ed. Agustín Millares Carlo, México, Fondo de Cultura Económica, 1951.

López de Gómara, Francisco, Historia general de las Indias, tomo I, Madrid, Calpe, 1922.

López de Recalde, Juan, «Carta del contador Juan López de Recalde al Obispo de Burgos dándole cuenta de la llegada al puerto de las Muelas de la nao S. Antonio, una de las que componían la Armada de Magallanes, de la cual se separó en el Estrecho», en José Toribio Medina, Colección de documentos inéditos para la historia de Chile, tomo I, Santiago de Chile, Imprenta Ercilla, 1888, pp. 162-170. 
Medina, José Toribio, Colección de documentos inéditos para la historia de Chile desde el viaje de Magallanes hasta la Batalla de Maipo. 1518-1818, tomo I, Santiago de Chile, Imprenta Ercilla, 1888.

Merino, Abelardo, Estudios histórico-críticos sobre Magallanes, Madrid, Imprenta del Patronato de Huérfanos de Intendencia e Intervención Militar, 1917.

Nilsson, Martin P, A History of Greek Religion, trad. Frederick J. Fielden, London, Oxford University Press, 1925.

Ortega, Casimiro de, Resumen histórico del primer viaje hecho alrededor del mundo, emprendido por Hernando de Magallanes, y llevado a feliz término por Juan Sebastián del Cano, Madrid, Imprenta Real de la Gaceta, 1769.

Pastells, Pablo, El descubrimiento del Estrecho de Magallanes en conmemoración del IV Centenario, vol. 1, Madrid, Sucesores de Rivadeneyra, 1920.

Pigafetta, Francisco Antonio, Primer viaje en torno del globo, Madrid, Calpe, 1922.

Queiroz Velloso, José Maria de, Fernão de Magalhães. A vida e a viagem, Lisboa, Editorial Imperio, 1941.

Raglan, Fitzroy R. S., The Hero. A Study in Tradition, Myth, and Drama, Westport, Greenwood Press, 1975 [1936].

Sarmiento de Gamboa, Pedro, Viaje al estrecho de Magallanes por el capitán Pedro Sarmiento de Gamboa en los años 1579-1580, Madrid, Imprenta Real de la Gaceta, 1768.

Transilvano, Maximiliano, Relación escrita por Maximiliano Transilvano de cómo y por quién y en qué tiempo fueron descubiertas y halladas las islas Molucas, en José Toribio Medina, Colección de documentos inéditos para la historia de Chile, tomo I, Santiago de Chile, Imprenta Ercilla, 1888. 